Article

\title{
Three New Sesquiterpene Aryl Esters from the Mycelium of Armillaria mellea
}

\section{Chien-Chih Chen ${ }^{1,2}$, Yueh-Hsiung Kuo ${ }^{3,4}$, Jing-Jy Cheng ${ }^{5}$, Ping-Jyun Sung ${ }^{6,7}$, Ching-Li Ni ${ }^{1}$, Chin-Chu Chen ${ }^{8}$ and Chien-Chang Shen ${ }^{5, *}$}

1 Department of Biotechnology, HungKuang University, Sha Lu, Taichung 433, Taiwan; E-Mails: ccchen@sunrise.hk.edu.tw (C.-C.C.); alyssum15@yahoo.com.tw (C.-L.N.)

2 Department of Nursing, HungKuang University, Sha Lu, Taichung 433, Taiwan

3 Department of Chinese Pharmaceutical Sciences and Chinese Medicine Resources, China Medical University, Taichung 404, Taiwan; E-Mail: kuoyh@mail.cmu.edu.tw

4 Department of Biotechnology, Asia University, Taichung 413, Taiwan

5 National Research Institute of Chinese Medicine, Ministry of Health and Welfare, Peitou, Taipei 112, Taiwan; E-Mail: verona@nricm.edu.tw

6 Graduate Institute of Marine Biology, National Dong Hwa University, Pingtung 944, Taiwan; E-Mail: pjsung@nmmba.gov.tw

7 National Museum of Marine Biology and Aquarium, Pingtung 944, Taiwan

8 Biotechnology Center, Grape King Bio Ltd., Chung Li, Taoyuan 320, Taiwan;

E-Mail: gkbioeng@grapeking.com.tw

* Author to whom correspondence should be addressed; E-Mail: ccshen@nricm.edu.tw;

Tel.: +886-2-2820-1999 (ext. 8581); Fax: +886-2-2826-4276.

Academic Editor: Thomas J. Schmidt

Received: 9 April 2015 / Accepted: 26 May 2015 / Published: 29 May 2015

\begin{abstract}
Three new sesquiterpene aryl esters and eight known compounds were isolated from the EtOH extract of the mycelium of Armillaria mellea. The structures of new compounds were established by analysis of their spectroscopic data. Some of the isolates showed cytotoxicity to a variety of cancer cell lines, including MCF-7, H460, HT-29, and CEM.
\end{abstract}

Keywords: sesquiterpene aryl esters; Armillaria mellea; Tricholomataceae; cytotoxicity 


\section{Introduction}

Armillaria mellea (Tricholomataceae) is a fungus symbiotic with the Chinese medicinal herb "Tianma" (Gastrodia elata Blume). The fruiting bodies of A. mellea have been used in Traditional Chinese Medicine for the treatment of hypertension, headache, insomnia, dizziness, and vertigo. Recently, the cultured mycelium of $A$. mellea became a health food in Taiwan and China and its tablets are used to treat geriatric patients with palsy, headache, insomnia, dizziness, and neurasthenia [1-5]. Previous chemical studies of $A$. mellea reported the isolation of a number of sesquiterpene aromatic esters, in which the tricyclic 5-6-4 protoilludane or protoilludene alcohols were esterified with orsellinic acid or its derivatives [1-3,6-12]. Some of the sesquiterpene aryl esters exhibited cytotoxic activities against human cancer cells. Among these sesquiterpene aryl esters, arnamial showed cytotoxicity against MCF-7, CCRF-CEM, HCT-116, and Jurkat T cells, but melledonal C only showed cytotoxic activity against CCRF-CEM cells [11]. Armillaridin was reported to exhibit cytotoxicity against MCF-7, HeLa, K562, and Jurkat T cells [12]. In addition to inhibiting the growth of the cancer cells, armillaridin also enhanced radiosensitivity of human esophageal cancer cells and there might be potential to integrate armillaridin with radiotherapy for esophageal cancer treatment [13]. Moreover, 4-O-methylarmillaridin showed cytotoxicity against MCF-7 and Jurkat T cells and dehydroarmillyl orsellinate showed cytotoxicity against MCF-7 and K562 cells [12]. Recently, armillarikin was reported to inhibit growth and induce apoptosis in human leukaemic K562, U937, and HL-60 cells [14]. In this paper, we describe the isolation and structural elucidation of three new sesquiterpene aryl esters from the mycelium of $A$. mellea, as well as the cytotoxic activities of the isolated components [15].

\section{Results and Discussion}

The EtOH extract of the mycelium of A. mellea was partitioned with EtOAc and $\mathrm{H}_{2} \mathrm{O}$. The EtOAc layer was chromatographed repeatedly to afford three new compounds, 1-3 (Figure 1), along with eight known compounds: 6'-chloromelleolide F (4) [16], 13-hydroxymelleolide K (5) [17], armillaricin (6) [3], armillaridin (7) [1], armillarikin (8) [2], melleolide F (9) [11], melledonal C (10) [18], and melledonal B (11) [18]. The structures of these new compounds were established by their spectroscopic data and the known compounds were identified by comparison of their NMR data with those reported in the literature.

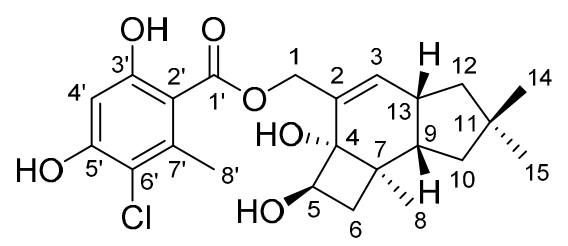

1

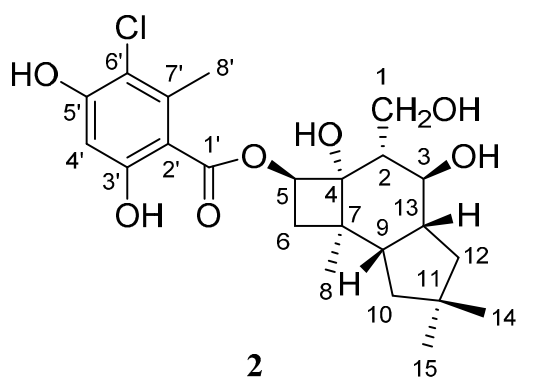

2

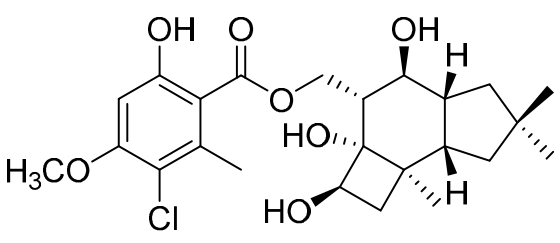

3

Figure 1. The structures of 1-3 isolated from the mycelium of Amillaria mellea.

Compound 1 was obtained as a colorless solid. Its ESIMS spectrum showed two peaks at $\mathrm{m} / z 459$ and 461 , which were attributed to $[\mathrm{M}+\mathrm{Na}]^{+}$and $[\mathrm{M}+2+\mathrm{Na}]^{+}$ions, respectively. The ratio of their 
intensities was about 3:1, suggesting the presence of a chlorine atom in compound 1 . The molecular formula $\mathrm{C}_{23} \mathrm{H}_{29} \mathrm{ClO}_{6}$ was deduced from FABHRMS and NMR (Table 1) spectra, which indicated that there were nine double bond equivalents. The ${ }^{13} \mathrm{C}$ and DEPT spectra displayed four methyl carbons at $\delta 19.7,22.3,32.1$, and 32.3 , four methylene carbons, including an oxymethylene group at $\delta 67.8$, five methine carbons, including one oxymethine group at $\delta 76.9$ and two olefinic or aromatic carbons at $\delta 102.7$ and 136.1, and ten quaternary carbons. Four of the quaternary carbons were oxygenated where one carbonyl, one aliphatic, and two aromatic carbons showed signals at $\delta 170.4,78.1,158.2$, and 161.8, respectively. The ${ }^{1} \mathrm{H}-\mathrm{NMR}$ spectrum of 1 exhibited four methyl singlets at $\delta 0.95,0.97$, 1.15 , and 2.62 and oxymethylene signals at $\delta 4.93(\mathrm{dt}, J=12.6,1.2 \mathrm{~Hz}$ ) and 5.19 (ddd, $J=12.6,1.8$, $0.6 \mathrm{~Hz}$ ). Two singlets at $\delta 5.87$ and 6.43 were derived from olefinic or aromatic protons. Moreover, a signal at $\delta 10.74$ revealed the presence of a chelated phenolic hydroxyl group. The one bond ${ }^{1} \mathrm{H}-{ }^{13} \mathrm{C}$ connectivities were analyzed by using HSQC data and protons attached to carbons were assigned. In the COSY spectrum of 1, proton $\mathrm{H}-9$ at $\delta 2.12$ showed correlations with $\mathrm{H}_{2}-10$ ( $\delta 1.35$ and 1.47) and $\mathrm{H}-13(\delta 2.73)$ and proton $\mathrm{H}-13$ also showed correlation with $\mathrm{H}_{2}-12(\delta 1.83)$, which indicated a linkage of C-10-C-9-C-13-C-12 (Figure 2). Besides, the linkages of C-3-C-13 and C-5-C-6 were deduced by COSY cross-peaks of $\mathrm{H}-3 / \mathrm{H}-13$ and $\mathrm{H}-5 / \mathrm{H}_{2}-6$. Further connectivities were established by long-range HMBC correlations shown in Figure 2. Cross-peaks of H-3/C-4,C-9,C-12 and H-13/C-2,C-7,C-10,C-11 revealed that a cyclopentane ring was fused to a cyclohexene ring. Moreover, HMBC cross-peaks of $\mathrm{H}-5 / \mathrm{C}-2, \mathrm{C}-4, \mathrm{C}-6$ and H-9/C-4,C-6 as well as the COSY correlation of H-5 and $\mathrm{H}_{2}-6$ suggested that a cyclobutane ring was fused to the cyclohexene ring. The HMBC data further showed cross-peaks of $\mathrm{H}_{3}-8 / \mathrm{C}-4, \mathrm{C}-6, \mathrm{C}-7, \mathrm{C}-9$ and $\mathrm{H}_{3}-14, \mathrm{H}_{3}-15 / \mathrm{C}-10-\mathrm{C}-12$, which indicated that one and two methyl groups were attached to $\mathrm{C}-7$ and $\mathrm{C}-11$, respectively. Besides, the correlations of $\mathrm{H}_{2}-1$ to $\mathrm{C}-2, \mathrm{C}-3$ and $\mathrm{C}-4$ suggested that an oxygenated methylene group was linked to C-2. Based on the above evidence, a protoillud-7-ene skeleton was deduced for compound 1 [6]. In addition to one double bond in the protoilludene moiety, six other unsaturated carbon signals and a total of nine double bond equivalents in 1 revealed that an aromatic ring could be a part of this compound. Furthermore, HMBC cross-peaks of $\mathrm{H}-8^{\prime} / \mathrm{C}-2^{\prime}, \mathrm{C}-6^{\prime}, \mathrm{C}-7^{\prime}$ and $\mathrm{H}-4^{\prime} / \mathrm{C}-2^{\prime}, \mathrm{C}-3^{\prime}, \mathrm{C}-5^{\prime}, \mathrm{C}-6^{\prime}$ were observed, which suggested the presence of a 3-chloro-4,6-dihydroxy-2-methylphenyl moiety. In the $\mathrm{HMBC}$ spectrum acquired in $\mathrm{CDCl}_{3}$, the proton signal $(\delta 11.08)$ of the hydroxyl group chelated to the carbonyl group at the aromatic ring showed correlations with C-2', C-3', and C-4', which indicated that the hydroxyl and the carbonyl groups were located at $\mathrm{C}-3^{\prime}$ and $\mathrm{C}-2^{\prime}$, respectively. Hence, the chlorine atom was suggested to be located at C-6'. The linkage of this benzoyl group to the oxygen atom at $\mathrm{C}-1$ was confirmed by the HMBC correlation of $\mathrm{H}_{2}-1$ to $\mathrm{C}^{-1}{ }^{\prime}$. The relative configuration of $\mathbf{1}$ was deduced from NOE experiments in $\mathrm{CDCl}_{3}$. The irradiation of $\mathrm{H}_{3}-8$ enhanced the signals of $\mathrm{H}-5$ and $\mathrm{H}-6 \mathrm{a}(\delta 1.87)$; however, the irradiation of H-9 enhanced the signals of H-6b ( $\delta 1.30), H-13$, and $\mathrm{H}_{3}-14$. Thus, H-6b, $\mathrm{H}-9, \mathrm{H}-13$, and $\mathrm{H}_{3}-14$ were on the same face of the protoilludene moiety and $\mathrm{H}-5, \mathrm{H}-6 \mathrm{a}$, and $\mathrm{H}_{3}-8$ were on the other face. In the ${ }^{13} \mathrm{C}-\mathrm{NMR}$ spectrum acquired in $\mathrm{CDCl}_{3}$, signals for $\mathrm{C}-2-\mathrm{C}-15$ resembled those of a protoilludene-type sesquiterpene, echinocidin $\mathrm{B}$, isolated from a mycelial culture of Echinodontium tsugicola, in which cis junctures of cyclohexene to both cyclobutane and cyclopentane rings were determined [19]. Accordingly, it was deduced that the cyclohexene ring in $\mathbf{1}$ was also fused to both cyclobutane and cyclopentane rings in a cis-fashion and the relative structure of 1 was established. Compound $\mathbf{1}$ was given the trivial name melleolide $\mathrm{N}$. 
Table 1. ${ }^{1} \mathrm{H}$ - and ${ }^{13} \mathrm{C}$-NMR data of compounds $\mathbf{1}-\mathbf{3}$ in acetone- $d 6{ }^{\mathrm{a}}$.

\begin{tabular}{|c|c|c|c|c|c|c|}
\hline \multirow{2}{*}{ Position } & \multicolumn{2}{|l|}{1} & \multicolumn{2}{|l|}{2} & \multicolumn{2}{|l|}{3} \\
\hline & $\delta_{H}^{b}$ & $\boldsymbol{\delta}_{\mathrm{C}}$ & $\delta_{H}{ }^{b}$ & $\boldsymbol{\delta}_{\mathrm{C}}$ & $\delta_{H}{ }^{b}$ & $\boldsymbol{\delta}_{\mathbf{C}}$ \\
\hline \multirow{2}{*}{1} & $4.93(\mathrm{dt}, 12.6,1.2)$ & \multirow{2}{*}{67.8} & $3.89(\mathrm{dd}, 10.8,4.8)$ & \multirow{2}{*}{62.9} & $4.68(\mathrm{dd}, 11.4,4.2)$ & \multirow{2}{*}{66.2} \\
\hline & $5.19(\mathrm{ddd}, 12.6,1.8,0.6)$ & & $4.03(\mathrm{dd}, 11.4,3.6)$ & & $4.71(\mathrm{dd}, 11.4,4.2)$ & \\
\hline 2 & & 132.0 & $2.09(\mathrm{~m})$ & 46.4 & $2.40(\mathrm{dt}, 10.8,4.2)$ & 43.8 \\
\hline 3 & 5.87 (br s) & 136.1 & $3.72(\mathrm{t}, 11.4)$ & 69.0 & $3.77(\mathrm{t}, 10.8)$ & 68.6 \\
\hline 4 & & 78.1 & & 81.4 & & 81.8 \\
\hline 5 & $4.33(\mathrm{t}, 8.4)$ & 76.9 & $5.33(\mathrm{t}, 8.4)$ & 77.2 & $4.19(t, 8.4)$ & 73.4 \\
\hline \multirow[b]{2}{*}{6} & $1.38(\mathrm{dd}, 10.8,9.0)$ & \multirow[b]{2}{*}{36.4} & $1.85(\mathrm{dd}, 10.8,9.0)$ & \multirow[b]{2}{*}{34.5} & $1.54(\mathrm{dd}, 10.2,8.4)$ & \multirow[b]{2}{*}{37.0} \\
\hline & $1.75(\mathrm{dd}, 10.8,8.4)$ & & $1.95(\mathrm{dd}, 10.8,7.8)$ & & $1.71(\mathrm{dd}, 10.8,8.4)$ & \\
\hline 7 & & 38.0 & & 39.0 & & 37.7 \\
\hline 8 & $1.15(\mathrm{~s})$ & 22.3 & $1.16(\mathrm{~s})$ & 22.3 & $1.06(\mathrm{~s})$ & 22.5 \\
\hline 9 & $2.12(\mathrm{~m})$ & 45.4 & $2.16(\mathrm{~m})$ & 48.1 & $2.09(\mathrm{~m})$ & 48.3 \\
\hline 10 & $\begin{array}{c}1.35(\mathrm{dd}, 12.6,7.2) \\
1.46(\mathrm{t}, 12.6)\end{array}$ & 42.3 & $1.46(\mathrm{~m})$ & 44.4 & \multirow[t]{2}{*}{$1.44(\mathrm{~m})$} & 44.7 \\
\hline 11 & & 38.5 & & 36.7 & & 36.7 \\
\hline \multirow{2}{*}{12} & $1.45(\mathrm{~d}, 13.2)$ & \multirow{2}{*}{48.3} & $1.52(\mathrm{dd}, 13.8,7.8)$ & \multirow{2}{*}{43.4} & $1.52(\mathrm{dd}, 13.8,7.8)$ & \multirow{2}{*}{43.6} \\
\hline & $1.83(\mathrm{dd}, 13.2,8.4)$ & & $1.98(\mathrm{~d}, 14.4)$ & & $1.97(\mathrm{~m})$ & \\
\hline 13 & $2.73($ br t, 7.8$)$ & 40.2 & $2.00(\mathrm{~m})$ & 47.5 & $1.97(\mathrm{~m})$ & 47.9 \\
\hline 14 & $0.97(\mathrm{~s})$ & 32.3 & $0.99(\mathrm{~s})$ & 32.4 & $0.99(\mathrm{~s})$ & 32.4 \\
\hline 15 & $0.95(\mathrm{~s})$ & 32.1 & $1.09(\mathrm{~s})$ & 32.7 & $1.07(\mathrm{~s})$ & 32.7 \\
\hline $1^{\prime}$ & & 170.4 & & 171.1 & & 169.0 \\
\hline $2^{\prime}$ & & 109.0 & & 108.3 & & 110.4 \\
\hline $3^{\prime}$ & & 161.8 & & 162.4 & & 160.9 \\
\hline $4^{\prime}$ & $6.43(\mathrm{~s})$ & 102.7 & $6.45(\mathrm{~s})$ & 102.6 & $6.45(\mathrm{~s})$ & 99.6 \\
\hline $5^{\prime}$ & & 158.2 & & 158.6 & & 159.4 \\
\hline $6^{\prime}$ & & 114.7 & & 114.8 & & 115.2 \\
\hline $7^{\prime}$ & & 140.4 & & 140.2 & & 139.8 \\
\hline $8^{\prime}$ & $2.62(\mathrm{~s})$ & 19.7 & $2.62(\mathrm{~s})$ & 19.9 & $2.57(\mathrm{~s})$ & 18.9 \\
\hline $3^{\prime}-\mathrm{OH}$ & 10.74 (br s) & & 10.97 (br s) & & & \\
\hline $5^{\prime}-\mathrm{OH}$ & 9.42 (br s) & & 9.56 (br s) & & & \\
\hline $5^{\prime}-\mathrm{OCH}_{3}$ & & & & & $3.89(\mathrm{~s})$ & 55.6 \\
\hline
\end{tabular}

${ }^{\text {a }}$ Spectra recorded at $600 \mathrm{MHz}$ for ${ }^{1} \mathrm{H}-\mathrm{NMR}$ and $150 \mathrm{MHz}$ for ${ }^{13} \mathrm{C}-\mathrm{NMR} ;{ }^{\mathrm{b}}$ Multiplicities and $J$ values (in $\mathrm{Hz}$ ) are in parentheses.
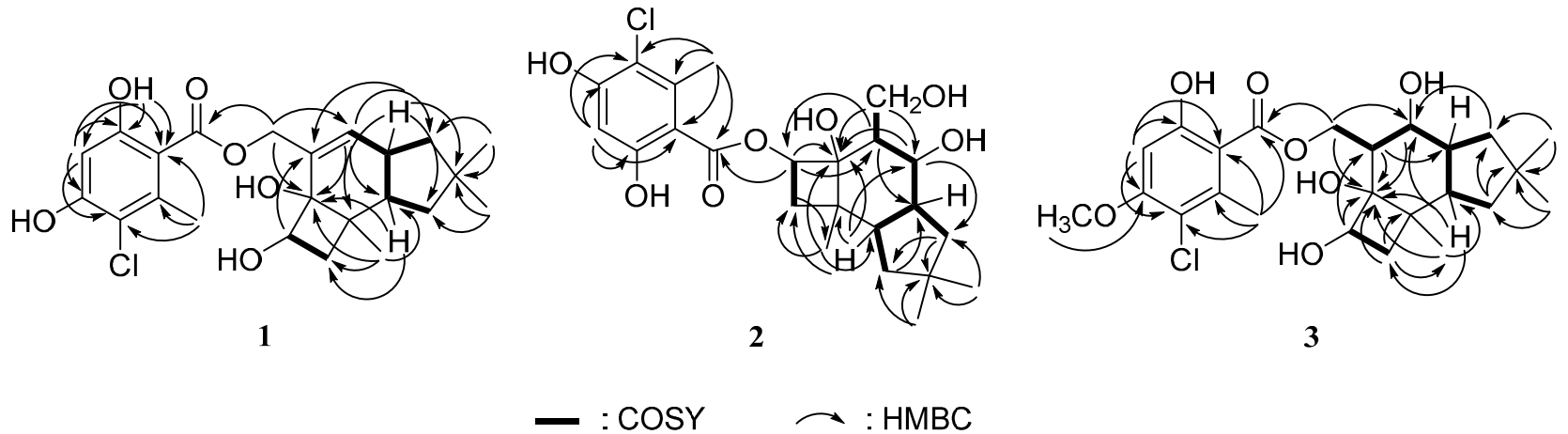

Figure 2. COSY and selected HMBC correlations of 1-3. 
Compound 2 gave a molecular formula of $\mathrm{C}_{23} \mathrm{H}_{31} \mathrm{ClO}_{7}$, which was deduced from its ESIHRMS and NMR (Table 1) spectra. Its ${ }^{13} \mathrm{C}$ and DEPT NMR spectra showed four methyl at $\delta 19.9,22.3,32.4$, and 32.7 , four methylene, six methine, and nine quaternary carbons. In addition to a carbonyl group with a signal at $\delta 171.1$, six carbons were oxygenated, which included one oxymethylene signal at $\delta 62.9$, two oxymethine signals at $\delta 69.0$ and 77.2, one aliphatic quaternary carbon signal at $\delta 81.4$, and two aromatic carbon signals at $\delta 158.6$ and 162.4. The carbon signals above $100 \mathrm{ppm}$ were almost the same as the signals of 3-chloro-4,6-dihydroxy-2-methylbenzoyl group in 1, suggesting the presence of this benzoyl group in $\mathbf{2}$. The ${ }^{1} \mathrm{H}-\mathrm{NMR}$ spectrum of $\mathbf{2}$ exhibited four methyl groups at $\delta 0.99,1.09(6 \mathrm{H})$, and 2.62. Besides, it showed two signals at $\delta 3.89(\mathrm{dd}, J=10.8,4.8 \mathrm{~Hz})$ and $4.03(\mathrm{dd}, J=11.4,3.6 \mathrm{~Hz}$ ), which correlated to the carbon signal at $\delta 62.9$ in the HSQC spectrum and were attributed to an oxymethylene group. Moreover, two signals at $\delta 3.72(\mathrm{t}, J=11.4 \mathrm{~Hz})$ and $5.33(\mathrm{t}, J=8.4 \mathrm{~Hz}$ ) correlating to the carbon signals at $\delta 69.0$ and 77.2, respectively, indicated the presence of two oxymethine groups. A signal at $\delta 6.45$ (s) was also observed and the proton correlated to the carbon resonating at $\delta$ 102.6, suggesting that they were in an aromatic ring. Its $\mathrm{HMBC}$ spectrum (Figure 2) displayed cross-peaks of $\mathrm{H}_{2}-1 / \mathrm{C}-2-\mathrm{C}-4$, H-3/C-1,C-4,C-12, H-5/C-2,C-4,C-6, H3-8/C-4,C-6,C-7,C-9, and $\mathrm{H}_{2}-12 / \mathrm{C}-3, \mathrm{C}-10, \mathrm{C}-11, \mathrm{C}-13-\mathrm{C}-15$, which revealed a protoilludane skeleton for 2 with C-1, C-3, C-4, and $\mathrm{C}-5$ oxygenated. The ${ }^{13} \mathrm{C}-\mathrm{NMR}$ data of the protoilludane moiety in $\mathrm{CD}_{3} \mathrm{OD}$ were almost the same as those in 5'-methoxy-6'-chloroarmillane [12], which suggested that the structures of the protoilludane moieties in 2 and 5'-methoxy-6'-chloroarmillane were the same. The linkage of 3-chloro-4,6dihydroxy-2-methylbenzoyl group to the oxygen atom at C-5 was confirmed by the HMBC correlation of H-5 to C-1'. In the NOESY spectrum, the cross-peaks of $\mathrm{H}_{3}-14 / \mathrm{H}-9, \mathrm{H}-12 \mathrm{~b}(\delta 1.52)$, H-9/H-6b ( $\delta$ 1.85), and $\mathrm{H}-6 \mathrm{~b} / \mathrm{H}-2$ revealed that $\mathrm{H}-2, \mathrm{H}-6 \mathrm{~b}, \mathrm{H}-9, \mathrm{H}-12 \mathrm{~b}$, and $\mathrm{H}_{3}-14$ were on the same face of the protoilludane moiety. Cross-peaks of $\mathrm{H}-3 / \mathrm{H}_{3}-15, \mathrm{H}-12 \mathrm{a}\left(\delta\right.$ 1.98), $\mathrm{H}_{3}-8 / \mathrm{H}-5, \mathrm{H}-6 \mathrm{a}(\delta$ 1.95) indicated that $\mathrm{H}-3, \mathrm{H}-5, \mathrm{H}-6 \mathrm{a}, \mathrm{H}_{3}-8, \mathrm{H}-12 \mathrm{a}$, and $\mathrm{H}_{3}-15$ were on the other face. Furthermore, the large coupling constant of $11.2 \mathrm{~Hz}$ for $\mathrm{H}-3$ indicated that $\mathrm{H}-2$ and $\mathrm{H}-3$ were in a trans configuration and the hydroxymethyl and 3-OH groups were on opposite faces. Thus, the relative structure of $\mathbf{2}$ was determined and it was named melleolide Q. This compound is similar to 5'-methoxy-6'-chloroarmillane where a methoxyl group instead of a hydroxyl group is located at C-5' [12].

Compound 3 gave a molecular formula of $\mathrm{C}_{24} \mathrm{H}_{33} \mathrm{ClO}_{7}$ deduced from FABHRMS and NMR (Table 1) spectra. Its ${ }^{13} \mathrm{C}$-NMR spectrum displayed 24 signals, including a methoxyl signal at $\delta 55.6$ and a carbonyl signal at $\delta$ 169.0, and the signals for C-3, C-4, and C-8-C-15 were similar to those in 2. In the aromatic region, the signals resembled those in $\mathbf{2}$ except that the signal for $\mathrm{C}-4^{\prime}$ shifted from $\delta$ 102.6 to 99.6. In the HMBC spectrum (Figure 2), the methoxyl protons showed correlation to C-5', which indicated that the methoxyl group was attached to $\mathrm{C}-5^{\prime}$ carbon of the aromatic ring. The ${ }^{1} \mathrm{H}-\mathrm{NMR}$ spectrum of $\mathbf{3}$ was also similar to that of $\mathbf{2}$ except for the signals of $\mathrm{H}_{2}-1, \mathrm{H}-2, \mathrm{H}-5$, and $\mathrm{H}_{2}-6$ as well as one additional signal at $\delta 3.89$ (s) attributed to a methoxyl group. Signals for $\mathrm{H}_{2}-1$ shifted downfield to $\delta 4.68(\mathrm{dd}, J=11.4,4.2 \mathrm{~Hz})$ and $4.71(\mathrm{dd}, J=11.4,4.2 \mathrm{~Hz})$ from $\delta 3.89$ and 4.03; signals for H-2 shifted downfield to $\delta 2.40(\mathrm{dt}, J=10.8,4.2 \mathrm{~Hz}$ ) from $\delta 2.09$. Moreover, H-5 signal shifted upfield from $\delta 5.33$ to $4.19(\mathrm{t}, J=8.4 \mathrm{~Hz})$ and the signals of $\mathrm{H}_{2}-6$ shifted upfield from $\delta 1.85$ and 1.95 to $\delta 1.54(\mathrm{dd}, J=10.2,8.4 \mathrm{~Hz})$ and $1.71(\mathrm{dd}, J=10.8,8.4 \mathrm{~Hz})$. Therefore, the benzoyloxy group in 3 was suggested to be linked to $\mathrm{C}-1$, which was confirmed by the HMBC correlation of $\mathrm{H}_{2}-1$ to $\mathrm{C}-1^{\prime}$. The stereochemistry of $\mathbf{3}$ was established by the NOESY spectrum and the coupling constant 
of H-2 and H-3. The NOESY cross-peaks of $\mathrm{H}_{3}-14 / \mathrm{H}-9, \mathrm{H}-12 \mathrm{~b}(\delta 1.52), \mathrm{H}-9 / \mathrm{H}-6 \mathrm{~b}(\delta 1.54), \mathrm{H}-3 / \mathrm{H}-12 \mathrm{a}$ $\left(\delta\right.$ 1.97), and $\mathrm{H}-5 / \mathrm{H}_{3}-8, \mathrm{H}-6 \mathrm{a}(\delta 1.71)$ and the large coupling constant of $10.8 \mathrm{~Hz}$ for $\mathrm{H}-3$ revealed that its relative configuration was the same as that in $\mathbf{2}$. Accordingly, the relative structure of $\mathbf{3}$ was determined and it was named melleolide $\mathrm{R}$.

The isolated compounds from A. mellea were tested in vitro for cytotoxicity to a variety of human cancer cell lines including MCF-7, H460, HT-29, and CEM and the results are summarized in Table 2. Compounds 2-4 and 6-9 showed cytotoxicity to MCF-7 cells, in which compound 2 was most cytotoxic. Compounds 1, 4, and 6-9 exhibited comparable cytotoxicity against H460 cells. Compounds 1 and $\mathbf{6}$ showed stronger cytotoxicity to HT-29 cells than other tested compounds. Compounds 1, 3, and 5-7 showed comparable cytotoxicity to human leukemia cells. Among all tested compounds, 6 exhibited cytotoxicity to all of these cancer cells. Compounds 1-5 and 7-9 showed selective cytotoxicity and compounds $\mathbf{1 0}$ and $\mathbf{1 1}$ were inactive to these cancer cell lines.

Table 2. Cytotoxicity of the isolated compounds from A. mellea against several cancer cell lines a.

\begin{tabular}{ccccc}
\hline \multirow{2}{*}{ Compound } & \multicolumn{4}{c}{$\mathbf{I C}_{\mathbf{5 0}}(\boldsymbol{\mu M})$} \\
\cline { 2 - 5 } $\mathbf{1}$ & $\mathbf{M C F}-\mathbf{7}$ & $\mathbf{H 4 6 0}$ & $\mathbf{H T - 2 9}$ & $\mathbf{C E M}$ \\
\hline $\mathbf{2}$ & $56.5 \pm 4.2$ & $5.5 \pm 0.6$ & $7.1 \pm 0.8$ & $5.4 \pm 0.3$ \\
$\mathbf{3}$ & $1.5 \pm 0.1$ & $80.0 \pm 8.9$ & $54.2 \pm 4.7$ & $10.3 \pm 2.3$ \\
$\mathbf{4}$ & $3.7 \pm 0.3$ & $53.8 \pm 6.2$ & $18.7 \pm 3.2$ & $3.4 \pm 0.2$ \\
$\mathbf{5}$ & $4.8 \pm 0.5$ & $4.5 \pm 0.4$ & $56.7 \pm 4.5$ & $28.8 \pm 1.2$ \\
$\mathbf{6}$ & $>100$ & $>100$ & $32.1 \pm 3.6$ & $5.5 \pm 0.6$ \\
$\mathbf{7}$ & $4.8 \pm 0.4$ & $5.5 \pm 0.4$ & $4.6 \pm 0.3$ & $5.8 \pm 0.6$ \\
$\mathbf{8}$ & $1.7 \pm 0.2$ & $4.5 \pm 0.3$ & $42.1 \pm 5.1$ & $5.1 \pm 0.4$ \\
$\mathbf{9}$ & $8.4 \pm 0.8$ & $5.7 \pm 0.5$ & $34.7 \pm 4.6$ & $44.6 \pm 4.4$ \\
$\mathbf{1 0}$ & $>100$ & $5.1 \pm 0.2$ & $58.4 \pm 4.9$ & $41.2 \pm 3.4$ \\
$\mathbf{1 1}$ & $>100$ & $>100$ & $85.6 \pm 9.1$ & $49.6 \pm 5.2$ \\
$\mathbf{D o x}$ & $0.27 \pm 0.02$ & $0.01 \pm 0.005$ & $0.12 \pm 0.01$ & $0.09 \pm 0.01$ \\
\hline
\end{tabular}

a MCF-7, human breast cancer; H460, human lung cancer; HT-29, human colon cancer; CEM, human leukaemia. Dox: Doxorubicin as a positive control.

\section{Experimental Section}

\subsection{General Experimental Procedures}

Optical rotations were taken on a P-2000 digital polarimeter (JASCO, Tokyo, Japan). UV spectra were measured on a U-3310 spectrophotometer (Hitachi, Tokyo, Japan). IR spectra were recorded on an Avatar 320 FT-IR spectrophotometer (Nicolet, Madison, WI, USA). ${ }^{1} \mathrm{H}-,{ }^{13} \mathrm{C}-$, and 2D-NMR spectra were recorded on a VNMRS $600 \mathrm{MHz}$ spectrometer (Varian, Palo Alto, CA, USA). ESIMS and HRMS spectra were obtained on LCQ and Quest MAT 95XL spectrometers (Finnigan/Thermo, San Jose, CA, USA), respectively. HPLC was conducted on a model 1100 system (HP, Palo Alto, CA, USA) equipped with a G1311A QuatPump, a G1322A degasser, and a G1315B photodiode array detector set at $254 \mathrm{~nm}$. Semipreparative HPLC was performed using a reversed-phase column (Cosmosil 5C 18 -MS-II, $5 \mu \mathrm{m}, 10 \times 250 \mathrm{~mm}$ ) at a flow rate of $2.0 \mathrm{~mL} / \mathrm{min}$. 


\subsection{Source of Organism}

The strain of the fungus A. mellea (\# BCRC 36361) was purchased from the Food Industry Research and Development Institute, Hsinchu, Taiwan.

\subsection{Fermentation of Organism}

The strain BCRC 36361 was inoculated into $1 \mathrm{~L}$ of the medium $(1.0 \%$ glucose, $1.0 \%$ oat powder, $0.1 \%$ peptone, $0.1 \%$ yeast extract, $\mathrm{pH} 4.5)$ in a 2 -L Hinton flask at $25{ }^{\circ} \mathrm{C}$ on a rotary shaker $(120 \mathrm{rpm})$ for six days. The mycelium was aseptically transferred to a $500-\mathrm{L}$ fermenter containing $400 \mathrm{~L}$ of the above medium and incubated at $25{ }^{\circ} \mathrm{C}$ for ten days.

\subsection{Extraction and Isolation}

The mycelium of $A$. mellea $(9.0 \mathrm{~kg})$ was extracted with $95 \% \mathrm{EtOH}(50 \mathrm{~L})$ three times. The $95 \%$ EtOH soluble portion was concentrated to give the EtOH extract, which was partitioned with $\mathrm{H}_{2} \mathrm{O}$ and EtOAc. The EtOAc layer was chromatographed on silica gel column and eluted with $n$-hexane-EtOAc $(20: 1 \rightarrow 0: 1)$ to provide ten fractions (Fr-1-Fr-10). Fraction Fr-3 ( $n$-hexane/EtOAc $=5: 1)$ was concentrated and recrystallized in $\mathrm{MeOH}$ to afford armillaricin $(6,114 \mathrm{mg})$. Fraction Fr-4 (n-hexane/EtOAc $=5: 1)$ was purified by semi-preparative reversed-phase $\mathrm{HPLC}\left[\mathrm{H}_{2} \mathrm{O} / \mathrm{CH}_{3} \mathrm{CN}(15: 85,0 \mathrm{~min}) \rightarrow \mathrm{H}_{2} \mathrm{O} / \mathrm{CH}_{3} \mathrm{CN}\right.$ $(0: 100,20 \mathrm{~min})]$ to give armillaridin $(7,365 \mathrm{mg}, \mathrm{Rt}=18.53 \mathrm{~min})$. Fraction Fr-7 $(n$-hexane/EtOAc $=1: 1)$ was repeatedly chromatographed on silica gel $\left(\mathrm{CHCl}_{3} / \mathrm{MeOH}=50: 1 \rightarrow 20: 1\right)$ and Sephadex LH-20 $(\mathrm{MeOH})$ columns to yield armillarikin $(8,676 \mathrm{mg}), 2(42.9 \mathrm{mg}), 6$ '-chloromelleolide $\mathrm{F}$ (4, $57.7 \mathrm{mg})$, and melleolide $\mathrm{F}(\mathbf{9}, 37 \mathrm{mg})$. Fraction Fr-9 $(n$-hexane/EtOAc $=0: 1)$ was repeatedly chromatographed on silica gel $\left(\mathrm{CHCl}_{3} / \mathrm{MeOH}=30: 1 \rightarrow 20: 1\right)$, Sephadex LH-20 $\left(\mathrm{H}_{2} \mathrm{O} / \mathrm{MeOH}=3: 7\right)$, and RP-18 $\left(\mathrm{H}_{2} \mathrm{O} / \mathrm{MeOH}=2: 8\right)$ columns to afford two compounds, melledonal $\mathrm{C}(\mathbf{1 0}, 3.50 \mathrm{~g})$ and $\mathbf{1}(101 \mathrm{mg})$, and one sub-fraction Fr-9-1. Sub-fraction Fr-9-1 was further purified by chromatography on a RP-18 column $\left(\mathrm{H}_{2} \mathrm{O} / \mathrm{MeOH}=2: 8\right)$ to give $3(18 \mathrm{mg})$. Fraction Fr-10 ( $n$-hexane/EtOAc $\left.=0: 1\right)$ was repeatedly chromatographed on silica gel $\left(\mathrm{CHCl}_{3} / \mathrm{MeOH}=30: 1 \rightarrow 15: 1\right)$, Sephadex LH-20 $(\mathrm{MeOH})$, and RP-18 $\left(\mathrm{H}_{2} \mathrm{O} / \mathrm{MeOH}=3: 7\right)$ columns to afford 13-hydroxymelleolide $\mathrm{K}(\mathbf{5}, 595 \mathrm{mg})$ and melledonal B (11, $118 \mathrm{mg})$.

\subsubsection{Melleolide N (1)}

Colorless powder; $[\alpha]_{D}^{25}-25$ (c 0.05, MeOH); UV (MeOH) $\lambda_{\max }(\log \varepsilon) 307$ (3.65), 261 (3.91), 213 (4.45) nm; IR (KBr) $v_{\max } 3528,1631,1592,1461,1425,1310,1243,1128,1081 \mathrm{~cm}^{-1} ;{ }^{1} \mathrm{H}-$ and ${ }^{13} \mathrm{C}-\mathrm{NMR}$ data: see Table 1; ESIMS $m / z(\%) 459[\mathrm{M}+\mathrm{Na}]^{+}(100), 461$ (36); FABHRMS $m / z 437.1732$ $[\mathrm{M}+\mathrm{H}]^{+}$(calcd for $\mathrm{C}_{23} \mathrm{H}_{30} \mathrm{ClO}_{6}[\mathrm{M}+\mathrm{H}]^{+}, 437.1731$ ).

\subsubsection{Melleolide Q (2)}

Colorless powder; $[\alpha]_{D}^{25}-70$ (c $\left.0.05, \mathrm{MeOH}\right)$; UV (MeOH) $\lambda_{\max }(\log \varepsilon) 310$ (3.44), 263 (3.78), 215 (4.20) nm; IR (KBr) $v_{\max }$ 3400, 2950, 2868, 1655, 1608, 1313, 1241, 1160, 1099, $1029 \mathrm{~cm}^{-1}$; 
${ }^{1} \mathrm{H}-$ and ${ }^{13} \mathrm{C}-\mathrm{NMR}$ data: see Table 1; ESIMS $m / z(\%) 477[\mathrm{M}+\mathrm{Na}]^{+}$(100), 479 (33); ESIHRMS $m / z$ $453.1684[\mathrm{M}-\mathrm{H}]^{-}$(calcd for $\mathrm{C}_{23} \mathrm{H}_{30} \mathrm{ClO}_{7}[\mathrm{M}-\mathrm{H}]^{-}, 453.1675$ ).

\subsubsection{Melleolide R (3)}

Colorless powder; $[\alpha]_{D}^{25}-10(c 0.06, \mathrm{MeOH}) ; \mathrm{UV}(\mathrm{MeOH}) \lambda_{\max }(\log \varepsilon) 303$ (3.61), 258 (3.95), 216 (4.47) nm; IR (KBr) $v_{\max } 3500,2951,2863,1648,1600,1453,1366,1319,1240,1101,1042 \mathrm{~cm}^{-1}$; ${ }^{1} \mathrm{H}$ - and ${ }^{13} \mathrm{C}-\mathrm{NMR}$ data: see Table 1; FABMS $\mathrm{m} / \mathrm{z}(\%) 469[\mathrm{M}+\mathrm{H}]^{+}$; FABHRMS $\mathrm{m} / z$ 469.1991 $[\mathrm{M}+\mathrm{H}]^{+}$(calcd for $\left.\mathrm{C}_{24} \mathrm{H}_{34} \mathrm{ClO}_{7}[\mathrm{M}+\mathrm{H}]^{+}, 469.1993\right)$.

\subsection{Cell Culture}

Four cancer cell lines, MCF-7, H460, HT-29, and CEM, were derived from the American Type Culture Collection (Manassas, VA, USA) and were maintained in DMEM or RPMI medium supplemented with $2 \mathrm{mM}$ L-glutamine and 10\% heat-inactivated fetal bovine serum (FBS) under standard culture conditions. The cell viability and cell number were determined by the Trypan Blue dye-exclusion method.

\subsection{Cancer Cell Cytotoxicity Assay}

To assess cell viability, the alamar blue (AB) assay (dye purchased from Biosource International, Nivelles, Belgium) was used as previously described [20]. This involved aspirating medium at the end of each treatment period and adding $100 \mu \mathrm{L}$ of fresh medium containing $10 \% v / v \mathrm{AB}$ to control and treated wells. Plates were incubated at $37{ }^{\circ} \mathrm{C}$ for $6 \mathrm{~h}$ prior to measuring the absorbance at $540 \mathrm{~nm}$ and at $595 \mathrm{~nm}$ wavelengths using a spectrophotometric plate reader. Experimental data were normalized to control values.

\section{Conclusions}

Three new sesquiterpene aryl esters, melleolides N (1), Q (2), and R (3), together with eight known compounds 4-11 were isolated from the EtOH extract of the mycelium of Armillaria mellea. Nine isolates showed cytotoxicity to a variety of cancer cell lines, including MCF-7, H460, HT-29, and CEM. Among the isolates, compound 6 exhibited cytotoxicity to all of these cancer cells and compounds 1-5 and 7-9 showed selective cytotoxicity.

\section{Acknowledgments}

This work was financially supported by National Science Council, Taiwan (NSC97-2323-B-077-002 and NSC98-2323-B-241-001). Additional financial support at CMU under the Aim for Top University Plan of the Ministry of Education, Taiwan and Taiwan Ministry of Health and Welfare Clinical Trial and Research Center of Excellence (MOHW104-TDU-B-212-113002) was provided. 


\section{Author Contributions}

Chien-Chih Chen and Chien-Chang Shen conceived and designed the experiments and wrote the paper. Ching-Li Ni performed the experiments. Chien-Chih Chen, Chien-Chang Shen, Yueh-Hsiung Kuo, and Ping-Jyun Sung analyzed the spectroscopic data and determined the chemical structures of the natural products. Jing-Jy Cheng contributed to the bioassays. Chin-Chu Chen contributed to the fermentation of the mycelium.

\section{Conflicts of Interest}

The authors declare no conflict of interest.

\section{References and Notes}

1. Yang, J.; Chen, Y.; Feng, X.; Yu, D.; Liang, X. Chemical constituents of Armillaria mellea mycelium I. Isolation and characterization of armillarin and armillaridin. Planta Med. 1984, 50, 288-290.

2. Yang, J.S.; Su, Y.L.; Wang, Y.L.; Feng, X.Z.; Yu, D.Q.; Cong, P.Z.; Tamai, M.; Obuchi, T.; Kondoh, H.; Liang, X.T. Isolation and structures of two new sesquiterpenoid aromatic esters: Armillarigin and armillarikin. Planta Med. 1989, 55, 479-481.

3. Yang, J.S.; Chen, Y.W.; Feng, X.Z.; Yu, D.Q.; He, C.H.; Zheng, Q.T.; Yang, J.; Liang, X.T. Isolation and structure elucidation of armillaricin. Planta Med. 1989, 55, 564-565.

4. Watanabe, N.; Obuchi, T.; Tamai, M.; Araki, H.; Omura, S.; Yang, J.S.; Yu, D.Q.; Liang, X.T.; Huan, J.H. A novel $N^{6}$-substituted adenosine isolated from Mi Huan Jun (Armillaria mellea) as a cerebral-protecting compound. Planta Med. 1990, 56, 48-52.

5. Gao, L.W.; Li, W.Y.; Zhao, Y.L.; Wang, J.W. The cultivation, bioactive components and pharmacological effects of Armillaria mellea. Afr. J. Biotechnol. 2009, 8, 7383-7390.

6. Midland, S.L.; Izac, R.R.; Wing, R.M.; Zaki, A.I.; Munnecke, D.E.; Sims, J.J. Melleolide, a new antibiotic from Armillaria mellea. Tetrahedron Lett. 1982, 23, 2515-2518.

7. Arnone, A.; Cardillo, R.; Nasini, G. Structures of melleolides B-D, three antibacterial sesquiterpenoids from Armillaria mellea. Phytochemistry 1986, 25, 471-474.

8. Donnelly, D.M.X.; Quigley, P.F.; Coveney, D.J.; Polonsky, J. Two new sesquiterpene esters from Armillaria mellea. Phytochemistry 1987, 26, 3075-3077.

9. Donnelly, D.M.X.; Hutchinson, R.M.; Coveney, D.; Yonemitsu, M. Sesquiterpene aryl esters from Armillaria mellea. Phytochemistry 1990, 29, 2569-2572.

10. Yang, J.S.; Su, Y.L.; Wang, Y.L.; Feng, X.Z.; Yu, D.Q.; Liang, X.T. Two novel protoilludane norsesquiterpenoid esters, armillasin and armillatin, from Armillaria mellea. Planta Med. 1991, 57, 478-480.

11. Misiek, M.; Williams, J.; Schmich, K.; Hüttel, W.; Merfort, I.; Salomon, C.E.; Aldrich, C.C.; Hoffmeister, D. Structure and cytotoxicity of arnamial and related fungal sesquiterpene aryl esters. J. Nat. Prod. 2009, 72, 1888-1891. 
12. Bohnert, M.; Miethbauer, S.; Dahse, H.M.; Ziemen, J.; Nett, M.; Hoffmeister, D. In vitro cytotoxicity of melleolide antibiotics: Structural and mechanistic aspects. Bioorg. Med. Chem. Lett. 2011, 21, 2003-2006.

13. Chi, C.W.; Chen, C.C.; Chen, Y.J. Therapeutic and radiosensitizing effects of armillaridin on human esophageal cancer cells. Evid. -Based Complement. Altern. Med. 2013, 2013, doi:10.1155/2013/459271.

14. Chen, Y.J.; Wu, S.Y.; Chen, C.C.; Tsao, Y.L.; Hsu, N.C.; Chou, Y.C.; Huang, H.L. Armillaria mellea component armillarikin induces apoptosis in human leukemia cells. J. Funct. Foods 2014, 6, 196-204.

15. Some contents in this paper were filed for US patent application (Pub. No. US2011/0262561 A1); however, the application was later abandoned due to some concerns.

16. Bohnert, M.; Nützmann, H.W.; Schroeckh, V.; Horn, F.; Dahse, H.M.; Brakhage, A.A.; Hoffmeister, D. Cytotoxic and antifungal activities of melleolide antibiotics follow dissimilar structure-activity relationships. Phytochemistry 2014, 105, 101-108.

17. Kobori, H.; Sekiya, A.; Suzuki, T.; Choi, J.H.; Hirai, H.; Kawagishi, H. Bioactive sesquiterpene aryl esters from the culture broth of Armillaria sp. J. Nat. Prod. 2015, 78, 163-167.

18. Arnone, A.; Cardillo, R.; Nasini, G.; Meille, S.V. Secondary mould metabolites. Part 19. Structure elucidation and absolute configuration of melledonals B and C, novel antibacterial sesquiterpenoids from Armillaria mellea. X-ray molecular structure of melledonal C. J. Chem. Soc. Perkin Trans. 1 1988, 3, 503-510.

19. Shiono, Y.; Seto, T.; Kamata, M.; Takita, C.; Suzuki, S.; Murayama, T.; Ikeda, M. Protoilludane-type sesquiterpenes, echinocidins $\mathrm{A}$ and $\mathrm{B}$, from a mycelial culture of Echinodontium tsugicola. Z. Naturforsch. 2004, 59, 925-929.

20. Lu, M.K.; Cheng, J.J.; Lin, C.Y.; Chang, C.C. Purification, structural elucidation, and anti-inflammatory effect of a water-soluble 1,6-branched 1,3- $\alpha$-D-galactan from cultured mycelia of Poria cocos. Food Chem. 2010, 118, 349-356.

Sample Availability: Samples of the compounds $\mathbf{7}$ and $\mathbf{1 0}$ are available from the authors.

(C) 2015 by the authors; licensee MDPI, Basel, Switzerland. This article is an open access article distributed under the terms and conditions of the Creative Commons Attribution license (http://creativecommons.org/licenses/by/4.0/). 